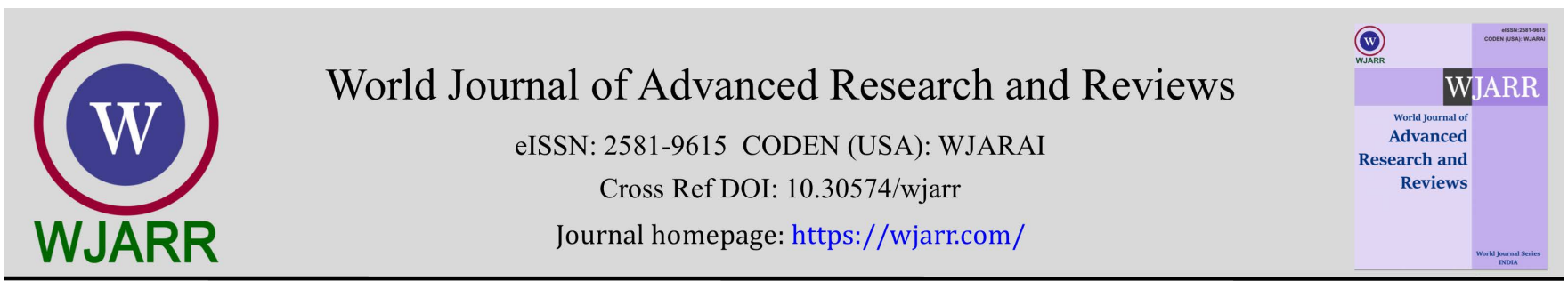

(RESEARCH ARTICLE)

Check for updates

\title{
Evaluation of agronomic descriptors of two cassava varieties (Manihot esculenta Crantz) on ten innovative substrates in Daloa (Côte d'Ivoire)
}

\author{
Serge Kouadio N'GONIAN * , Auguste-Denise Mambé BOYE and Junior Kévin Borel AKA \\ Laboratory for the Improvement of Agricultural Production; UFR Agroforestry, University Jean Lorougnon Guédé. BP150 \\ Daloa, Côte d'Ivoire.
}

World Journal of Advanced Research and Reviews, 2021, 11(03), 093-101

Publication history: Received on 31 July 2021; revised on 06 September 2021; accepted on 08 September 2021

Article DOI: https://doi.org/10.30574/wjarr.2021.11.3.0424

\begin{abstract}
In Côte d'Ivoire, cassava production is carried out by small-scale planters who use very few technical means and local cultivars that are not very productive and susceptible to diseases. The objective of this study is to maximize the recovery of cassava cuttings after planting. To this end, ten substrates of single, double, triple and quadruple composition were made from soil supplemented with sawdust, chicken droppings, carbonized rice husks and NPK 101818 to regenerate dehydrated cassava Bocou 1 and Yavo mini-cuttings. The recovery rate of the mini-cuttings was evaluated as well as the agro-morphological parameters of the seedlings for 21 days. Results showed that the recovery rate was very high on the carbonized rice husk substrate (86.5\% in Bocou 1 and $85.5 \%$ in Yavo). In addition, the substrates significantly influenced the growth parameters of the seedlings. Thus, the substrate composed of carbonized chicken-bale soil had the highest number of leaves, with 6 leaves per plant in Bocou 1 and 10 leaves in Yavo, with an average height ranging from $10.99 \pm 1.22$ (Bocou 1) to $20.23 \pm 1.16$ (Yavo). The results of this study will help orient the actors of the cassava sector towards a new cultivation technique.
\end{abstract}

Keywords: Cassava; Bocou 1; Yavo; Agronomic descriptors; Innovative substrate

\section{Graphical Abstract}

\footnotetext{
* Corresponding author: N'GONIAN Kouadio Serge

Laboratory for the Improvement of Agricultural Production ; UFR Agroforestry, Université Jean Lorougnon Guédé. BP150 Daloa, Côte d'Ivoire.
} 


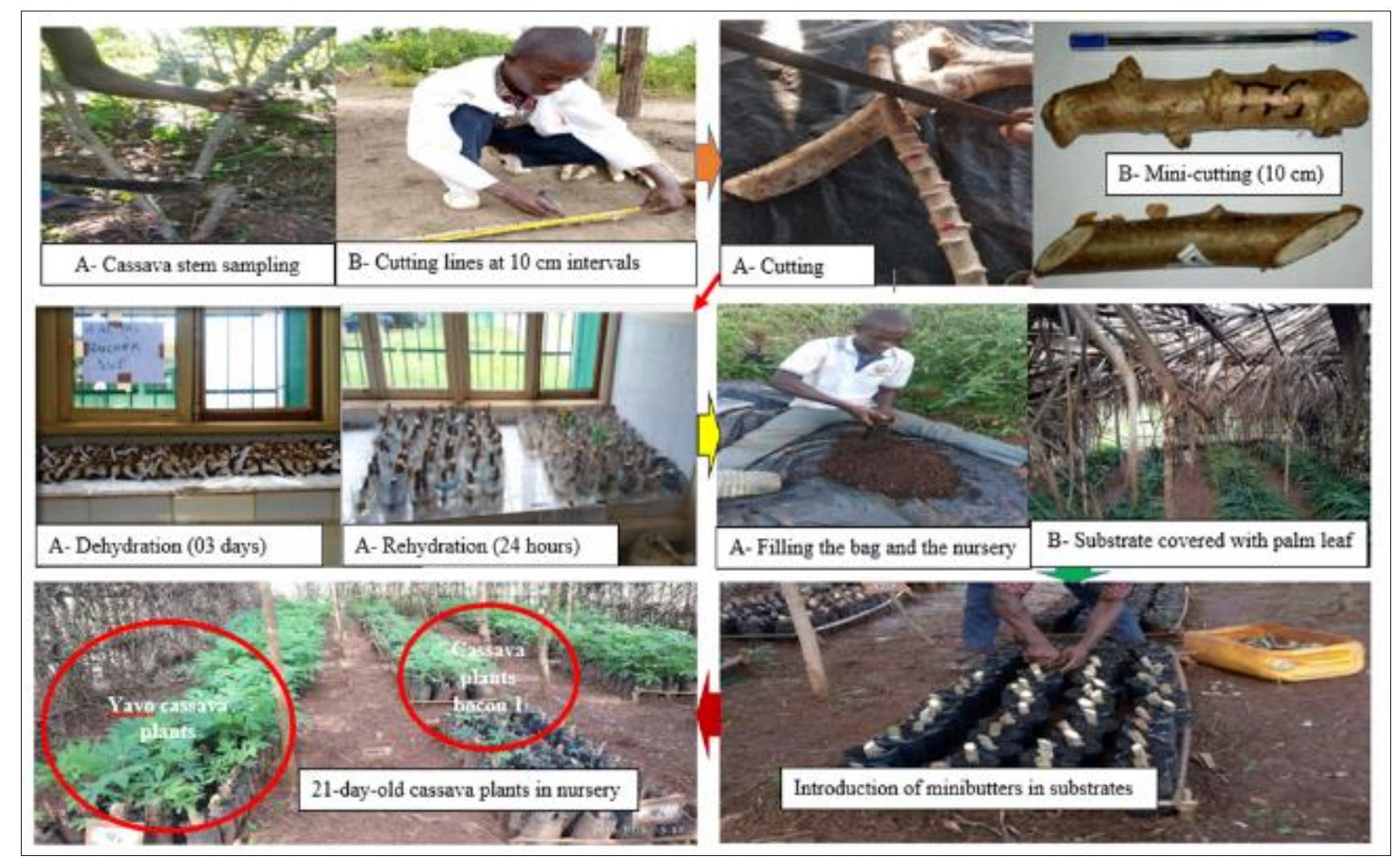

\section{Introduction}

Cassava (Manihot esculenta Crantz), originally from Latin America, was domesticated in Amazonia where it shares the same area of origin as groundnut, cocoa and rubber [1]. It was introduced in Africa by Portuguese merchants since the 16th century through various routes [2]; then in Côte d'Ivoire by AKAN immigrant populations coming from the South of Ghana, notably the Abouré and the Aladjan [3]. Cassava is one of the main food crops in Côte d'Ivoire just after yam, with a national production estimated at about 5 million t/year [4]. It contributes to human and animal nutrition but is also used for industrial purposes. There are more than twenty products derived from cassava in Côte d'Ivoire, including attiéké, cassava paste, which are traded nationally and internationally [5]. However, with the strong demographic growth and the rapid expansion of cassava cultivation, there has been a sharp increase in cultivated areas and continuous exploitation of the soil. In addition, cassava propagation is particularly vulnerable to adverse climatic conditions, as well as to pest and disease attacks. Stem cuttings may rapidly lose their viability through dehydration when exposed to the sun after planting. Thus, in order to overcome all these constraints of cassava production, this study was initiated with the objective of optimizing the regeneration of cassava cuttings after planting on improved substrates. Specifically, the aim is (i) to evaluate the effect of substrates on the regrowth of cassava mini-cuttings Bocou 1 and Yavo and (ii) to determine the impact of substrates on the agro-morphological parameters of the seedlings derived from these cuttings.

\section{Material and methods}

\subsection{Plant material}

The plant material used consists of mini-cuttings of improved cassava varieties (Bocou 1 and Yavo). The variety Yavo, previously called Okolyawo or TME7, described since 2000 [6], originated from the International Institute of Tropical Agriculture (IITA) and was introduced in Côte d'Ivoire in June 2002. The Bocou 1 variety is a cassava variety from the National Agricultural Research Center (CNRA) of Côte d'Ivoire.

\subsection{Technical equipment}

Several tools were used during this experiment. These included: three packages of polyethylene bags, a SONY digital camera with 20.1 mega pixels for photos, a shovel, a carbonizer, a walker, small dabas, signs, labels, a watering can, 25 $\mathrm{L}$ cans and $100 \mathrm{~kg}$ bags. 


\subsection{Preparation of substrates}

The different basic materials (soil, sawdust, chicken droppings, charred rice husks and NPK 1018 18) were collected. The decomposing soil, sawdust and chicken droppings were crumbled and then air-dried for 48 hours to remove some pathogens. For this purpose, ten substrates were made up:

- $\quad$ Substrate Control (no fertilizer): $100 \%$ soil ;

- $\quad$ Substrate 1 (S1): $50 \%$ soil + 50\% sawdust;

- $\quad$ Substrate 2 (S2): $50 \%$ soil + 50\% chicken droppings;

- Substrate 3 (S3): 50\% soil + 50\% carbonized rice husk;

- $\quad$ Substrate 4 (S1): $50 \%$ soil $+25 \%$ sawdust $+25 \%$ chicken droppings;

- Substrate 5 (S5): $50 \%$ soil $+25 \%$ chicken dung + 25\% carbonized rice husk;

- Substrate 6 (S6): $50 \%$ soil $+25 \%$ sawdust $+25 \%$ carbonized rice husk;

- $\quad$ Substrate 7 (S7): $25 \%$ soil $+25 \%$ sawdust $+25 \%$ chicken droppings $+25 \%$ carbonized rice husk

- $\quad$ Substrate 8 (S8) : $75 \%$ soil + $25 \%$ NPK 101818

- $\quad$ Substrate 9 (S7) : 50\% soil + 50\% NPK 1011818

\subsection{Experimental setup}

We arranged the substrates in 10 groups of 60 bags for each cassava variety under a shade house. Each group consisted of four (04) lines of 15 bags spaced $5 \mathrm{~cm}$ apart and $10 \mathrm{~cm}$ between the lines and covered with palm leaves (Figure 1).

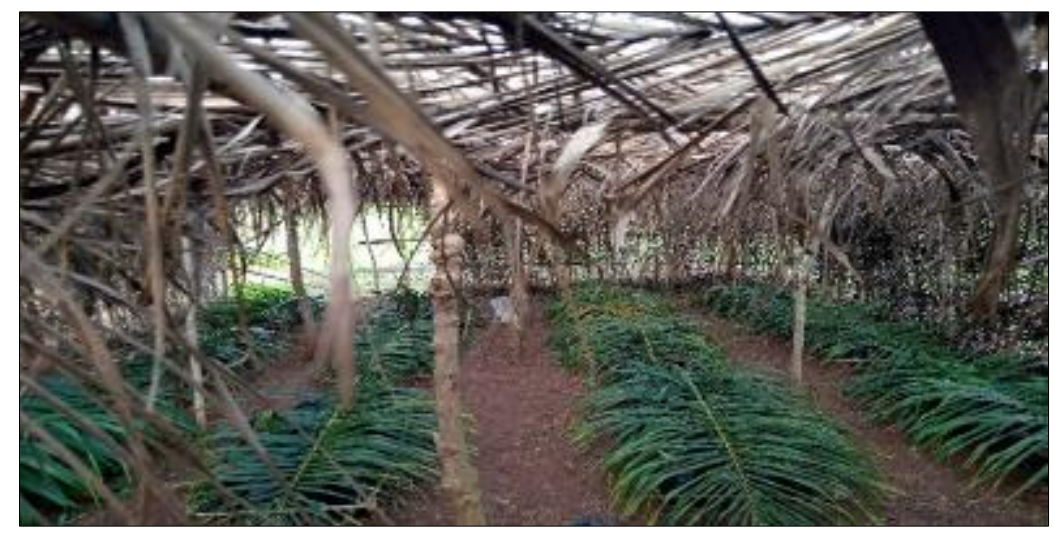

Figure 1 Substrates covered with palm leaves under the shade

\subsection{Selection and preparation of cuttings}
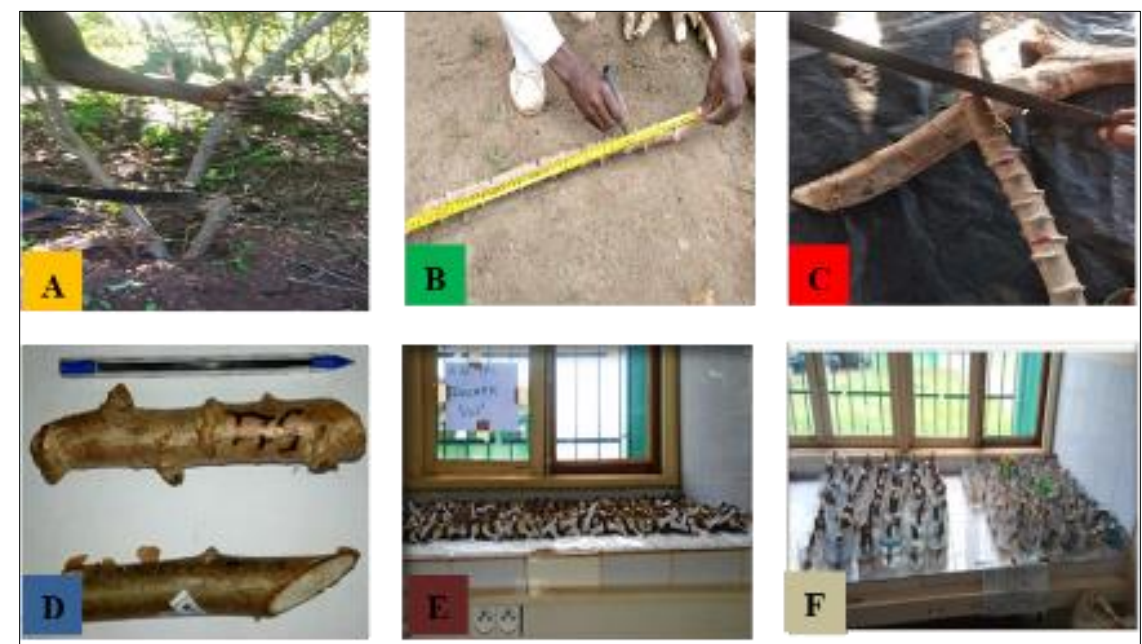

Figure 2 Preparation of cuttings: A- Cassava stem removal; B- Cutting lines at $10 \mathrm{~cm}$ intervals; C: Cutting; D: B- minicutting (10 cm); E: Dehydration (03 days); F: Rehydration (24 hours) 
Three days before planting, healthy stems of Bocou 1 and Yavo were taken from healthy, 12-month-old plants (Figure 2A). They were then cut into $10 \mathrm{~cm}$ long cuttings (mini-cuttings) with 2 to 3 nodes 15 to $20 \mathrm{~mm}$ in diameter (Figure 2B). Heavily woody or tender parts were removed. All cuts were made at a bevel with a machete (Figure 2C). The minicuttings obtained (Figure 2D) were put in dehydration for three (03) days (Figure 2E). At the end of the storage time, the mini-cuttings were rehydrated for 24 hours (Figure $2 \mathrm{~F}$ ).

\subsection{Planting}

One hour before planting, the substrates were abundantly watered, one watering can per formulation. Three quarters (3/4) of the mini-cuttings were then pushed into the substrates while orienting the buds upwards to ensure good growth of the seedlings. One thousand two hundred (1200) mini-cuttings were planted (Figure 3).
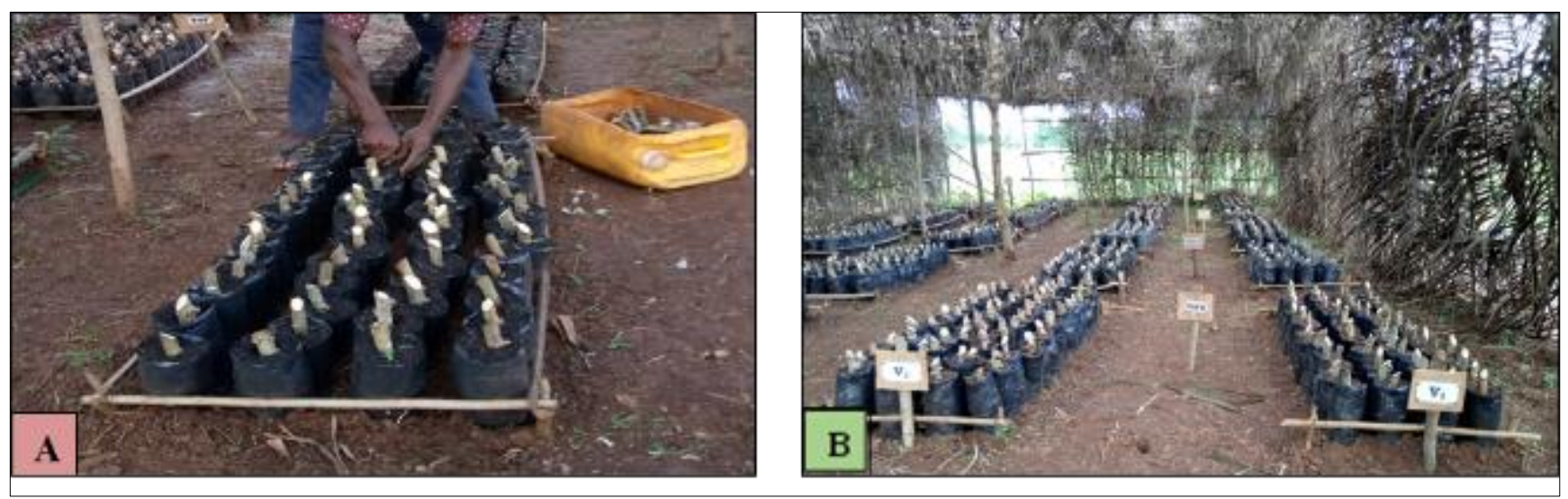

Figure 3 Planting and layout of substrates: A- Introduction of mini-cuttings into the substrates; B- Substrates containing mini-cuttings under the shade house

\subsection{Maintenance}

Maintenance concerns watering, weeding and replacement of unregenerate mini-cuttings. Indeed, in order to ensure the adequate maintenance of the nursery, we immediately watered the plantation. Then, the watering was limited to one watering every two days, preferably in the evening and to avoid watering the nursery after a heavy rainfall. In addition, weeding consisted in removing all the weeds that appeared on the surface of the substrates by hand and then those of the inter-rows with the hoe. Fourteen days after planting, the unregenerate mini-cuttings were replaced. Then, those partially emerged after watering were systematically covered with the corresponding substrate.

\subsection{Evaluation of agro-morphological parameters}

The agro-morphological descriptors that were studied were the recovery rate of dehydrated mini-cuttings, the number of leaves and stems and the height of the plants.

\subsection{Statistical analysis of the data}

The collected data were subjected to statistical tests using STATISTICA 7.1 software. An analysis of variance (ANOVA) was used to evaluate the effect of the substrates on the regeneration of mini-cuttings and the growth parameters of the plants. In case of significant differences between treatments, the Newman-Keuls test at the $5 \%$ threshold was used to classify them into homogeneous groups.

\section{Results}

\subsection{Recovery rate of mini-cuttings}

Table 1 shows that the recovery rate of mini-cuttings ranged from 62.93 to $86.5 \%$ for Bocou 1 and from 60.55 to $85.55 \%$ for Yavo. The highest values are observed on substrate S3 for Bocou 1 (86.5\%) and Yavo (85.55\%) respectively. On the other hand, the lowest recovery rates were observed on substrate S8 (62.93\% for Bocou 1 and 60.55\% for Yavo). The emergence of the dehydrated mini-cuttings is moderately high on the other substrates. We also note that the substrates offer more possibilities of regeneration to the dehydrated mini-cuttings of the Bocou 1 variety compared to the Yavo variety in the nursery. 
Table 1 Regrowth rate of dehydrated mini-cuttings of Bocou 1 and Yavo

\begin{tabular}{|c|c|c|}
\hline Substrates & Bocou 1 & Yavo \\
\hline Control & $76,77 \%$ & $68,11 \%$ \\
\hline $\mathrm{S}_{1} \%$ & $76,5 \%$ & $68,88 \%$ \\
\hline $\mathrm{S}_{2}$ & $80,07 \%$ & $78,88 \%$ \\
\hline $\mathrm{S}_{3}$ & $86,5 \%$ & $85,55 \%$ \\
\hline $\mathrm{S}_{4}$ & $79,75 \%$ & $74,99 \%$ \\
\hline $\mathrm{S}_{5}$ & $73,40 \%$ & $65,55 \%$ \\
\hline $\mathrm{S}_{6}$ & $83,72 \%$ & $79,44 \%$ \\
\hline $\mathrm{S}_{7}$ & $75,93 \%$ & $70,55 \%$ \\
\hline $\mathrm{S}_{8}$ & $62,93 \%$ & $60,55 \%$ \\
\hline $\mathrm{S}_{9}$ & $63,01 \%$ & $67,77 \%$ \\
\hline
\end{tabular}

Legend: Control: $100 \%$ soil; S1: $50 \%$ soil + $50 \%$ sawdust; S2: $50 \%$ soil + $50 \%$ chicken dung; S3: $50 \%$ soil + $50 \%$ charred rice husk); S4: $50 \%$ soil

+ $25 \%$ sawdust $+25 \%$ chicken dung; S5: $50 \%$ soil $+25 \%$ sawdust $+25 \%$ carbonized rice husk; S6: $50 \%$ soil $+25 \%$ chicken dung + $25 \%$ carbonized rice husk; S7: $25 \%$ soil + $25 \%$ sawdust + $25 \%$ chicken dung + $25 \%$ carbonized rice husk; S8: $50 \%$ soil + 50 \% NPK (10-18-18) S9: 50 $\%$ soil + $25 \%$ NPK (10-18-18).

\section{Effect of substrates on agro-morphological parameters}

\subsection{Average number of leaves}

Figure 4 presents the results of the average number of leaves per plant and per cassava variety according to the types of substrates. For the Bocou 1 variety, the plants growing in substrates control (Te), S1, S2 and S3, on the one hand, and S4, S7, S8 and S9 on the other hand, produced a similar number of leaves (6 leaves). On the other hand, the other plants from substrates S5 and S6 produced 5 leaves. As for the variety Yavo, the greatest number of leaves was recorded on the substrate S6 (10 leaves) against 7; 8 and 9 leaves respectively on the substrates S7, control (Te) and S5. However, the majority of the substrates produced 6 leaves.

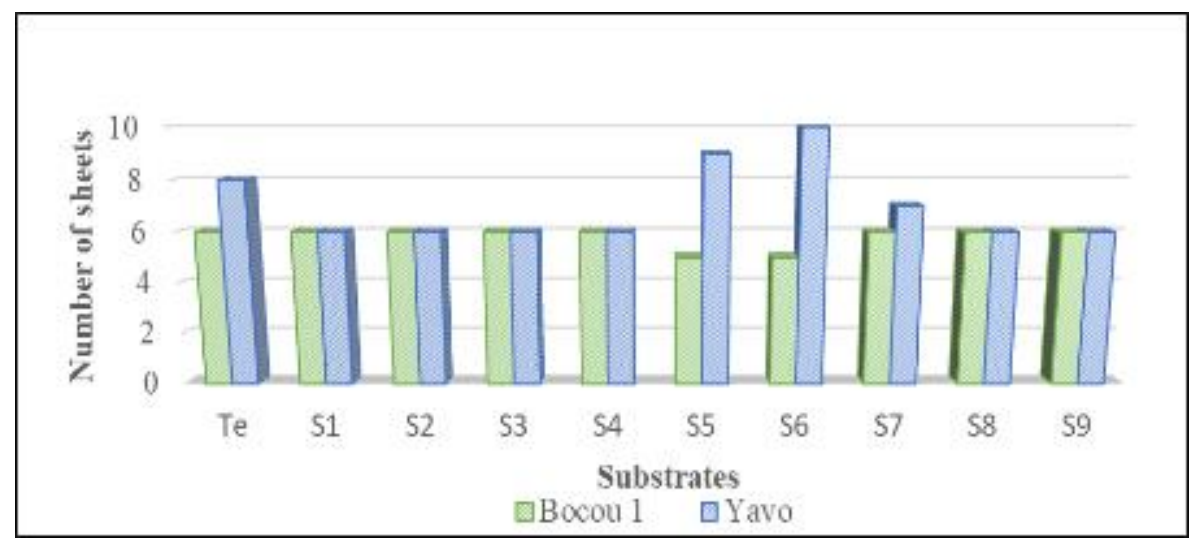

Figure 4 Effect of substrates on the number of leaves emitted by the plants

Legend: Control: $100 \%$ soil; S1: $50 \%$ soil + $50 \%$ sawdust; S2: $50 \%$ soil + $50 \%$ chicken dung; S3: $50 \%$ soil + $50 \%$ charred rice husk); S4: 50\% soil

$+25 \%$ sawdust $+25 \%$ chicken dung; S5: $50 \%$ soil + $25 \%$ sawdust $+25 \%$ carbonized rice husk; S6: $50 \%$ soil + $25 \%$ chicken dung + $25 \%$ carbonized rice husk; S7: $25 \%$ soil + $25 \%$ sawdust + $25 \%$ chicken dung + $25 \%$ carbonized rice husk; S8: $50 \%$ soil + 50 \% NPK (10-18-18) S9: 50 $\%$ soil + $25 \%$ NPK $(10-18-18)$.

\subsection{Average number of stems}

The results of the average number of stems per plant according to the substrates and variety are presented in figure 5 below. The analysis of this figure indicates that the average number of stems per plant varies according to the treatment and the varieties. The highest number of stems is observed in substrate S5 with a value of 2.44 for the variety Yavo 
against 1.22 in treatment S2 for Bocou 1 compared to the control(Te) Yavo $(2.17 \mathrm{~cm})$ and the control (Te) Bocou 1 (1.07). On the other hand, the lowest number of stems is recorded by treatments S9 (1.44) in Yavo and S8 (0.93) in Bocou 1. We also note no significant difference in the means of the other treatments in the Bocou 1 variety, whereas it is significant in the Yavo variety. It should therefore be said that the average number of stems per plant is significantly impacted by the substrates and the cassava variety.

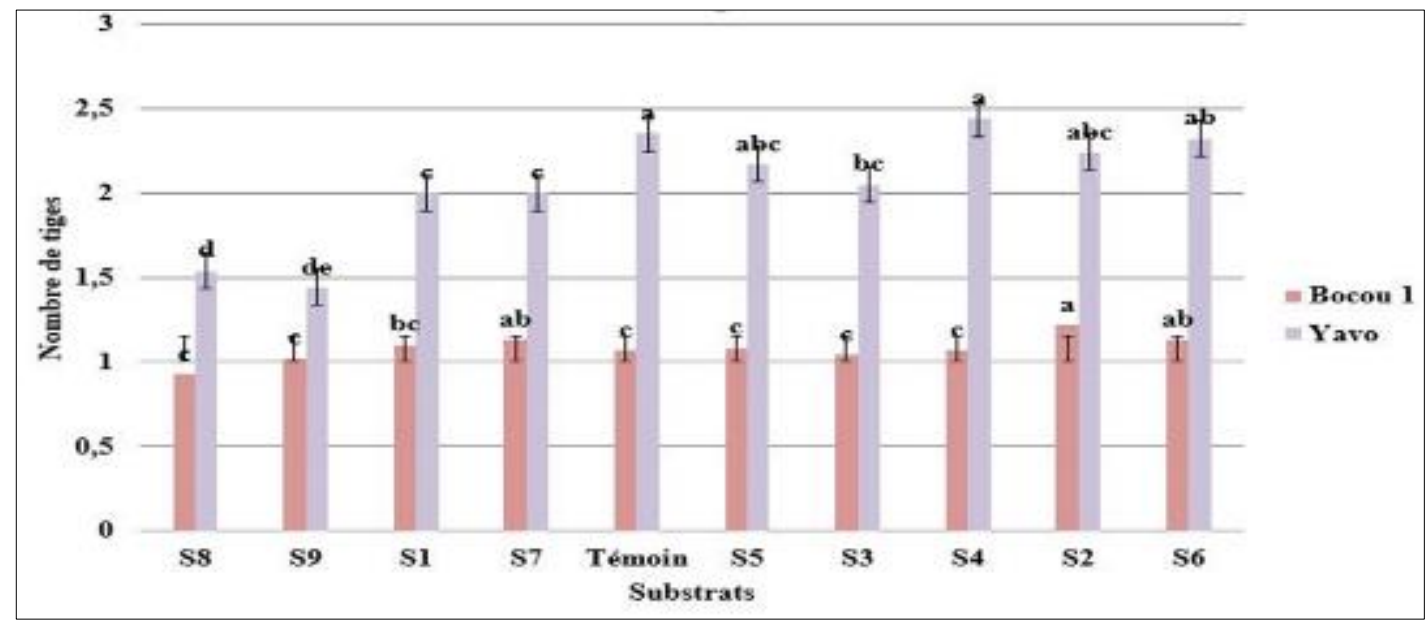

Figure 5 Effect of substrates on number of stems emitted by the mini-cuttings

Legend: Control: $100 \%$ soil; S1: $50 \%$ soil + $50 \%$ sawdust; S2: $50 \%$ soil + $50 \%$ chicken dung; S3: $50 \%$ soil + $50 \%$ charred rice husk); S4: 50\% soil

$+25 \%$ sawdust $+25 \%$ chicken dung; S5: $50 \%$ soil $+25 \%$ sawdust $+25 \%$ carbonized rice husk; S6: $50 \%$ soil $+25 \%$ chicken dung + $25 \%$ carbonized rice husk; S7: $25 \%$ soil + $25 \%$ sawdust + $25 \%$ chicken dung + $25 \%$ carbonized rice husk; S8: $50 \%$ soil + 50 \% NPK (10-18-18) S9: 50 $\%$ soil + $25 \%$ NPK $(10-18-18)$

\subsection{Average plant height}

Figure 6 presents the results of the effect of the treatments on the average height of the seedlings from the dehydrated mini-cuttings. The analysis of the figure reveals that the highest average height is observed in treatment S6 $(20.23 \mathrm{~cm}$ for Yavo) against $10.99 \mathrm{~cm}$ for Bocou 1 while the controls (Te) Yavo and Bocou 1 recorded $17.28 \mathrm{~cm}$ and $10.46 \mathrm{~cm}$ respectively. The lowest average height is observed in treatment S8 with average values of $2.43 \mathrm{~cm}$ for Bocou 1 and $11.12 \mathrm{~cm}$ for Yavo. The figure also shows a non-significant difference in the average height of the plants in the other treatments for the variety Bocou 1 because the values obtained are statistically identical. There is also a significant difference in the mean heights for the two varieties studied. This means that the average height of the plants is significantly influenced by the different treatments but also by the varieties.

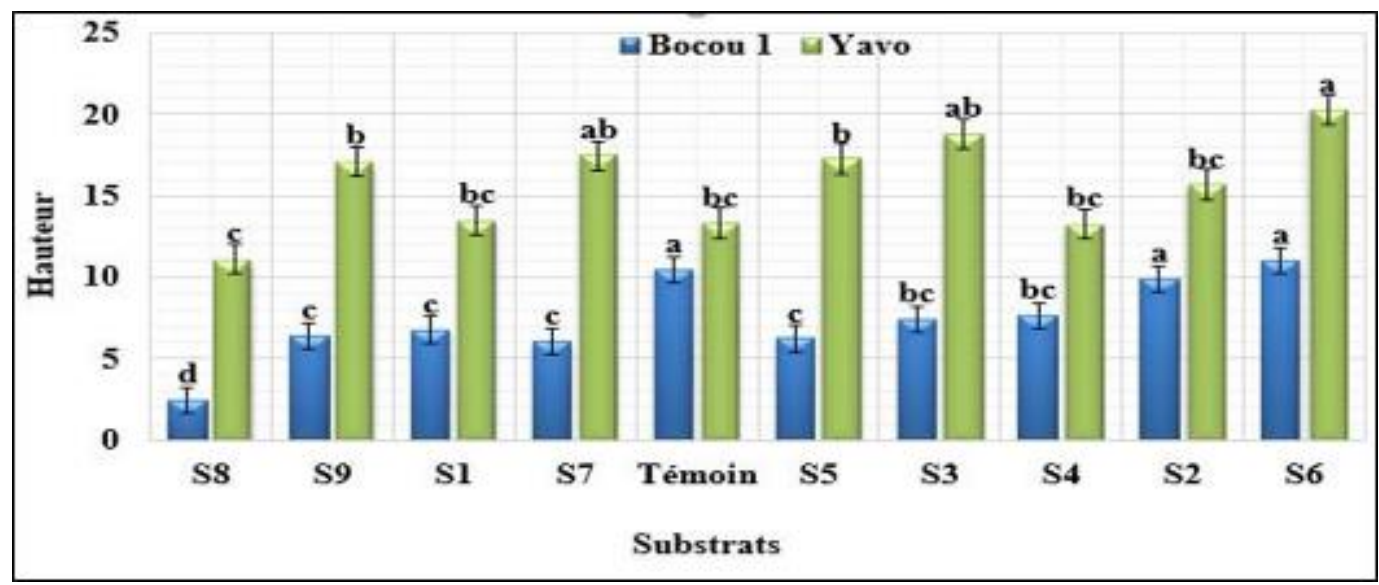

Figure 6 Effect of substrates on the height of Bocou 1 and Yavo plants

Legend: Control: $100 \%$ soil; S1: $50 \%$ soil + $50 \%$ sawdust; S2: $50 \%$ soil + $50 \%$ chicken dung; S3: $50 \%$ soil + $50 \%$ charred rice husk); S4: 50\% soil $+25 \%$ sawdust $+25 \%$ chicken dung; S5: $50 \%$ soil $+25 \%$ sawdust $+25 \%$ carbonized rice husk; S6: $50 \%$ soil $+25 \%$ chicken dung $+25 \%$ carbonized rice husk; S7: $25 \%$ soil + $25 \%$ sawdust + $25 \%$ chicken dung + $25 \%$ carbonized rice husk; S8: $50 \%$ soil + 50 \% NPK (10-18-18) S9: 50 $\%$ soil + $25 \%$ NPK $(10-18-18)$. 


\section{Discussion}

\subsection{Effect of substrates on minibouture recovery}

The results of the minibouture recovery study reveal that the variation in minibouture regeneration of Bocou 1 is dependent on each of the substrates. Substrates S2 and S6 induced better results on minibouture recovery. These results can be explained by the basic elements that compose the substrates and corroborate the observations of [7] on the species Lovoa trichilioides. Indeed, according to similar work carried out by [8] and [9], it appears that the appropriate substrate for agroforestry nurseries is a mixed composition. As for substrates supplemented with mineral fertilizer (NPK) at different doses (25\% and 50\%) gave the lowest yields with each variety. Our work is in accordance with that of [10] in the influence of the time of application of NPK on the growth and yield of maize (Zea mays L.) installed on a ferralsol. They showed that application of NPK at planting time induced low emergence rate. With respect to low recovery and seedling growth rates, the fertilizer applied at the time of seeding of the mini-cuttings induced a lower emergence than the other treatments. Water deficiency is thought to be responsible for this behavior. Indeed, water is a very important element of the plant. It participates in all metabolic activities. It also allows to attenuate the heat released by the decomposition of the fertilizer. However, in this study, the application of fertilizer at planting time coincided with a period of frequent water shortage. This would have dehydrated the mini-cuttings, thus inhibiting dormancy emergence. However, the maximum emergence rate did not exceed $80 \%$. This would confirm the burns observed on the mini-cuttings during the nursery, resulting in delayed mini-cuttings regeneration and seedling growth.

\subsection{Effect of substrates on seedling growth in the nursery}

\subsubsection{Effect of substrates on the number of leaves and stems}

The majority of seedlings growing in the substrates produced 6 leaves at Bocou 1 and Yavo. This could be due to the physical-chemical characteristics that allowed the plants to get a good supply of water and mineral salts, thus stimulating the growth of leaves and the emission of stems. Indeed, in order to grow, seedlings need the growth environment to provide them with three essential elements other than a physical support, namely water, oxygen and mineral elements [11]. In addition, these qualities may have led the S6 substrate to favor the production of 10 leaves, thus sequestering more carbon in the Yavo variety. These characteristics also induced the physiological awakening of dormant buds on the mini-cuttings. The number of leaves is a good indicator of a good supply of water and mineral salts and a good biomass production by the plant [12]. For example, the substrate S6 in addition to chicken droppings contains carbonized rice husks, rich in potassium also allowed the plants to develop dry matter and intervene directly in photosynthesis.

\subsubsection{Effect of substrates on plant height}

According to Randrianarison N plant growth can be evaluated by knowing the height of the stem, in which nitrogen plays an essential role [13]. Thus, the highest height was noted in the substrate S6 made up of carbonized chicken-rice husk soil. These results could be explained by the high content of mineral elements in this substrate and their physicalchemical characteristics. The good growth of the seedlings observed in the S6 substrate is due on the one hand to its richness in nutrients (especially nitrogen) and in trace elements provided by the chicken droppings, which would compensate for the possible natural deficiencies of the soil used. Indeed, the richness in nitrogen here translates into the fact that the magnesium contained in this substrate favors the absorption of nitrogen. On the other hand, the rapid growth of the seedlings in substrate S6 can be explained by the presence of carbonized rice husk, which incorporated into the soil improves the $\mathrm{pH}$, the aeration of the root zone, the water retention capacity of the soil, and the level of potash and magnesium exchange. It also favors the assimilation of phosphorus. Our results are in agreement with those of [14] in the response of Musa species to macro-propagation. He stated that the physical composition of the growth medium has an effect on the water and air supply to the growing seedlings. These results corroborate those of [15] in the effect of different growing media on the growth of Die fenbachia maculata. They also showed that the physical characteristics of the growth medium affect the vigor of the plant. In addition, according to Bégin $\mathrm{G}$ in the potential use of sawdust as a growing medium for greenhouse tomato: phytotoxicity, growth and productivity [16]; the substrate must have a good air and water retention capacity in order to maximize the feeding of the seedling because the physical characteristics of a substrate play a very important role in the control of the irrigation of the substrate and consequently, the growth, the yield and the quality of the seedlings produced. Our results are also in line with the work of [17] in the evaluation of substrates and seedlings produced in forest nurseries. They showed that substrates induced a better growth of seedlings in the nursery. However, the poor growth of the seedlings observed would be due to the fact that the other substrates were relatively poor in nutrients or had poor physical characteristics. Our results confirm those of 
[18] on the Influence of substrate composition on weaning of plantain (Musa sp) vivo plants. They showed that substrates consisting of soil (25\%) and sawdust (75\%) induced a low growth of seedlings.

\section{Conclusion}

The study showed that the regeneration rate is very high on carbonized rice husk soil substrates. In addition, the carbonized rice husk-soil substrate improved the agro-morphological parameters of cassava in the nursery. Therefore, substrates S3 and S6 can be recommended for the establishment of a cassava nursery. However, additional and diversified studies may be required for the productivity of dehydrated cassava mini-cuttings. They should take into account the yield parameters, the biochemical and organoleptic characterization of the tuberised roots of the minicuttings for the satisfaction of the present and future needs of the populations.

\section{Compliance with ethical standards}

\section{Acknowledgments}

Our thanks go to the Laboratory of Improvement of Agricultural Production of the University Jean Lorougnon of Daloa for the provision of plant material, as well as to the Head of the Scientific Research Department of the said university for his instructions.

\section{Disclosure of conflict of interest}

The authors declare that they have no competing interests.

\section{References}

[1] Olsen KM. SNPs, SSRs and inferences on cassava's origin. Plant Molecular Biology. 2004; 56: 517-526.

[2] IITA. Cassava in tropical Africa a reference manual. Ibadan, Nigeria. 1990.

[3] Akpingny KL, Koulou N. Cassava technical and economic data sheet. Edition ANADER, Côte d'Ivoire; 2017.

[4] Patricio MDV, Akoua A, Tran T, Konan A, Bancal V. The cassava value chain in Côte d'Ivoire. $3^{\text {rd }}$ ed. Agrinatura. Brussels: European Commission. 2018.

[5] N'Zué B, Zohouri GP, Djédji C, Tahouo O. Growing cassava well in Côte d'Ivoire; National Agricultural Research center, Abidjan, Côte d'Ivoire. 2013.

[6] Ayemou SA Study of the varietal behavior of new cassava clones (Manihot esculenta Crantz) in the Toumodi area (Central Côte d'Ivoire): case of Bringakro and Tontonou [Diploma of Advanced Studies, Agro-pedology]. Côte d'Ivoire: University of Abidjan-Cocody; 2000.

[7] Tchoundjeu Z, Leakey RRB. Vegetative propagation of Lovoa trichilioides: effects of provenance, substrate, auxins and leaf area. Jol of Tropl For Sci. 2001; 13: 116129.

[8] Weigel J. Practical Agroforestry: for use by field workers in dry tropical Africa. 1994.

[9] Ammari Y, Lamhamedi MS, Akrimi N, Zine El Abidine A. Composting of forest biomass and its use as growth substrate for seedling production in modern forest nurseries. Revue de l'I.N.A.T. 2003; 18: 99-119.

[10] Ilunga TH, Banza MJ, Lukusa ML, Mukunto KI, Malonga HL, Kanyenga LA, Nyembo KL. Influence of NPK application timing on growth and yield of maize (Zea mays L.) established on ferralsol. Jol of Appl Biosci. 2018; 127: $12794-12803$.

[11] Wolf B. The fertile triangle; The Interrelationship of air, water, and nutrients in maximizing soil productivity, Food Products Press, New York, USA. 1999.

[12] Ignoumba GM. Improvement of plantain productivity on sandy soils of the Congolese coast by the introduction of leguminous plants in understorey [End of study thesis for the diploma of engineer of rural development. Institute of Rural Development]. Congo: Marien Ngouabi University. 2011.

[13] Randrianarison N. Nursery management trials in recession tobacco cultivation: seedlings in beds and mini-pots. Determination of the effects of different substrate types on germination rate. Determination of the most appropriate sickling method [Final thesis for the diploma of agricultural engineer. Option: Agriculture]. University of Antananarivo. 2004. 
[14] Baiyeri KP. Response of Musa species to macro-propagation. 11: The effects of genotype, initiation and weaning media on sucker growth and quality in the nursery. Afri Jol of Biotech. 2005; 4(3): 229-234.

[15] Adams BA, Osikabor B, Abiola JK, Jayeoba OJ, ABIOLA IO. Effect of Different Growing Media on the Growth of Die ffenbachia maculata. In: Fasina AS, Olufolaji AO, Umeh VC (eds). The Role of Horticulture in Economie Development of Nigeria. Proceedings of the $21^{\text {st }}$ Annual Conference of the Horticultural Society of Nigeria, Held at School of Agriculture, Lagos State Polythechnic Sagamus Road, lkorodu, Lagos, Nigeria. 2003; 10-13.

[16] Bégin G. Potential use of sawdust as a growing medium for greenhouse tomato: phytotoxicity, growth and productivity [Master's thesis]. Québec: Laval University. 2008.

[17] M'Sadak Y, Elouaer MA, El Kamel R. Evaluation of substrates and seedlings produced in forest nursery. Boi and for tro. 2012; 313(3): 61-71.

[18] Mayeki JP, Ndong Biyo'OM, Ngnigone EC, Molouba F, Demikoyo D, Mibemu S, Effa B. Influence of substrate composition on weaning of plantain (Musa $s p$ ) vivoplants, Plant Biotechnology Laboratory IRAF- CENAREST in Sciences Sud N³. 2010. 